\title{
Relationship of Canopy Cover with TanDEM-X Features in a Tropical Peat Swamp Forest
}

\author{
Michael SCHLUND ${ }^{1,2}$, Felicitas VON PONCET ${ }^{2}$, \\ Steffen KUNTZ ${ }^{2}$ and Dirk H. HOEKMAN ${ }^{3}$ \\ ${ }^{1}$ Friedrich-Schiller-University Jena, Jena/Germany·michael.schlund@uni-jena.de \\ ${ }^{2}$ Astrium GEO-Information Services, Immenstaad/Germany \\ ${ }^{3}$ Wageningen University, Wageningen/Netherlands
}

This contribution was double-blind reviewed as extended abstract.

\begin{abstract}
Monitoring of tropical forests and peat swamp forests becomes increasingly important in order to reduce carbon emissions from deforestation and forest degradation. SAR systems are suitable for that purpose due to their weather independence and sensitivity for changes in time series. The TanDEM-X mission delivers global datasets of a single-pass SAR interferometer, which provides more information in comparison to normal X-band SAR acquisitions. In particular the interferometric coherence can be regarded as useful information because it is dependent on tree height and canopy cover representing stand structure, which are important parameters for monitoring of forests.
\end{abstract}

\section{Introduction}

Land-use changes due to anthropogenic activities affect natural carbon stocks impacting the global carbon cycle. Therefore, monitoring of tropical forests is important in the context of climate change. SAR (synthetic aperture radar) systems are a potential tool for monitoring tropical forests because of their weather and day/night independence. The bistatic TanDEM-X mission is a SAR mission, whose aim is to create a highly accurate global digital elevation model (KRIEGER et al. 2007). The two sensors of the TanDEM-X mission acquire data of the entire land mass several times. These data could therefore be used as the basis for homogeneous, large-scale and high-resolution land cover information surveys. Initial analysis implied that the TanDEM-X data is very useful to create accurate land cover maps (SCHLUND et al. 2012). This is mainly due to the usage of single-pass interferometric coherence which can be calculated from the interferometric analysis of the across-track interferometer TanDEM-X. The most significant advantage of the TanDEM-X constellation is the minimization of temporal decorrelation. Thus, the coherence is mainly influenced by volume decorrelation which carries information of the vegetation structure.

TORAÑO CAICOYA et al. (2012) already showed that it is possible to derive tree heights from the interferometric coherence of an operational TanDEM-X acquisition by inverting the Random Volume over Ground Model. Nevertheless, volume decorrelation is not only influenced by the size but also by the structure of the volume. Initial analysis with field 
measurements suggested that the interferometric coherence is also influenced by the degree of tree crown coverage (SCHLUND et al. 2012). However, the number of field samples was not sufficient to accomplish representative conclusions. This analysis was continued by using a LiDAR (Light Detection and Ranging) data set which is presented in this paper.

\section{Input Data and Study Site}

The LiDAR data was acquired on August 05, 2007 with a horizontal resolution of one meter. The LiDAR data was already classified and provided as a final product including a digital terrain model (DTM) and digital surface model (DSM). Figure 1 shows the extent of the LiDAR and TanDEM-X dataset. The TanDEM-X data was acquired on December 21, 2010 in horizontal polarization $(\mathrm{HH})$ in bistatic acquisition mode meaning that one sensor acts as transmitter and receiver (active) and the other one only as receiver (passive) of the SAR signal. This configuration is enabled by a close formation flight of the two satellites. The data were acquired in StripMap mode, resulting in a resolution of about $3 \mathrm{~m}$. The effective baseline that describes the effective distance between the two sensors was $163 \mathrm{~m}$.

The location of the study area in Kalimantan, Indonesia is illustrated in figure 1. Peat swamp forests represent a major part of the study area. Peat swamp forests have a crucial role in the context of global carbon emissions. However, many parts of the area have already been drained for agricultural use, raising the risk of destructive forest fires signifycantly.
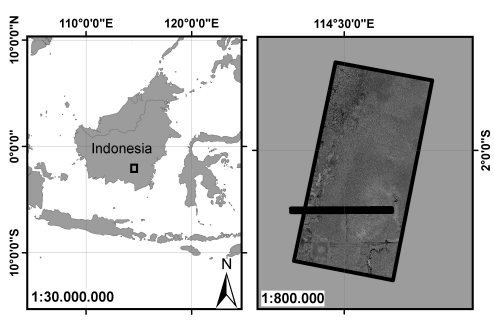

Fig. 1:

Location of the study area (left) \& extent of TanDEM$\mathrm{X}$ acquisiton (black frame with Amplitude image) \& LiDAR dataset (black stripe).

\section{Methods}

The active and passive amplitude were computed from the complex TanDEM-X dataset. Multi-looking with a factor of 3 in range direction and 2 in azimuth direction has been applied, in order to suppress speckle noise. This results in a resolution of about $6 \mathrm{~m}$ in both directions. The interferograms of the TanDEM-X acquisition were calculated and the flat earth was removed. Subsequently the interferometric coherence was estimated resulting in a range from 0 to 1 . The amplitudes and interferometric coherence were geocoded using the orbit parameters with a digital elevation model and resampled to a pixel size of $5 \mathrm{~m}$.

The difference of the two LiDAR height models (DSM - DTM) is the canopy height model (CHM) which represents the vegetation height and surface of the canopy ( $\mathrm{KOCH}$ et al. 2006). A local maximum filter is an appropriate method for detecting individual tree tops from a CHM (e.g. KOCH et al. 2006). Local maxima are detected, if the neighbouring pixels have a lower value than the central pixel of the filter mask. The crown topography has variations according to $\mathrm{KOCH}$ et al. (2006), resulting in multiple smaller tops for one 
individual tree or crown. Therefore, commission errors could occur in single tree detection. The local maxima algorithm was applied at a Gaussian-filtered canopy height model. The top of a tree crown should result in a local maximum and therefore, detected as an individual tree. The number of local maxima per unit area can thus provide information on the number of trees per unit area or the tree cover density (POPESCU \& WYNNE 2004).

\section{$4 \quad$ Results and Discussion}

A moderate correlation of coherence and the number of local maxima estimated from the LiDAR data is achieved with a coefficient of determination of 0.64 (Fig. 2). The relationship of active amplitude and the detected local maxima per hectare is also shown in Figure 2. Compared to the active amplitude with an $\mathrm{R}^{2}$ of 0.37 for linear and 0.54 for a logarithmic relationship a larger proportion of local maxima variation can be explained by the single-pass coherence. A comparison of the active and passive amplitude showed that there are no significant differences in the correlation of the amplitudes with the number of local maxima. The range of the interferometric coherence is between 0.7 and 0.86 . The values of the amplitude range between $-10 \mathrm{~dB}$ and $-8 \mathrm{~dB}$. The dynamic range of both features is small and therefore, it can be concluded that the sensitivity is limited.
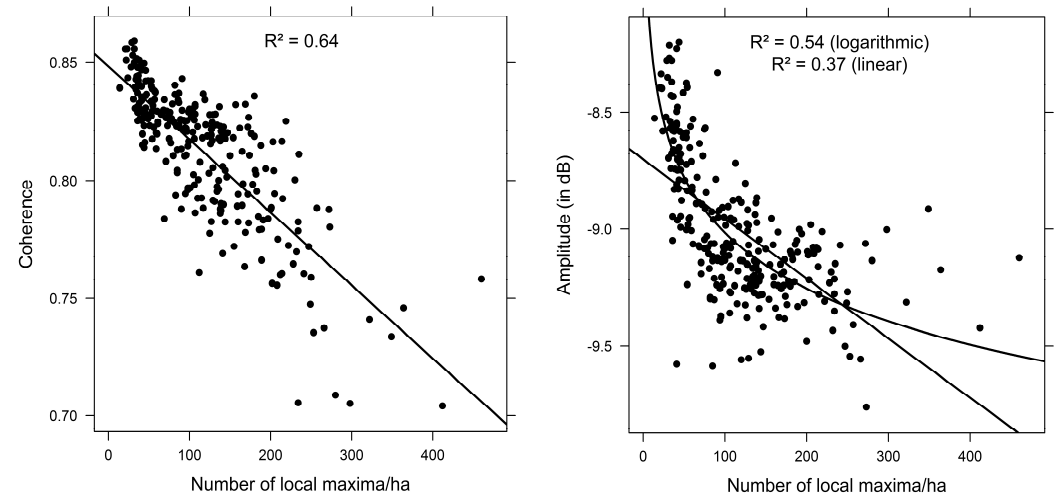

Fig. 2: Linear relationship of coherence (left) \& logarithmic relationship of active amplitude (right) with number of local maxima per hectare

However, the number of detected local maxima is not a perfect measure of canopy cover and can thus be misleading. Trees hidden by larger trees cannot be differentiated in the canopy height model and thus cannot be detected as a local maximum. Furthermore, omission errors arise when smaller trees are growing close to large trees. The smaller trees would also not generate a local maximum. Commission errors can occur when the crown is divided into different parts. Therefore, each part of that crown can create local maxima for one individual tree. Nevertheless, the number of local maxima is an indication of the number of trees in a unit area related to the canopy cover (POPESCU \& WYNNE 2004).

The results from this study imply that the volume decorrelation in TanDEM-X data and thus, the interferometric coherence is correlated to the forest structure. A high canopy cover leads to more volume decorrelation and hence, to lower coherence. The probability of 
direct, dihedral or trihedral backscattering increases due to the side-looking geometry and the resulting wave interaction with twigs, branches and stems, if the crown cover is low. The direct or multiple backscattering processes at low tree cover density are also visible in the correlation of the active amplitude with the number of local maxima per hectare. These processes produce high backscatter values which occur mainly with a low number of local maxima per hectare. This explanation is in line with the high coherence measured in more open forest areas. In contrast, closed crown coverage with high numbers of local maxima per hectare results in more volume scattering. This is confirmed by the volume decorrelation of the interferometric coherence.

\section{Conclusion and Outlook}

The results show that the volume decorrelation in the TanDEM-X data is influenced by the structure and the canopy cover. The correlation of the single-pass coherence with the number of local maxima implies that the probability of volume decorrelation is higher with a more closed or denser volume. Even though the dynamic range of TanDEM-X coherence is limited and depends on the baseline, it provides valuable information for forest stratification that cannot be obtained by repeat-pass coherence measurements. The repeatpass coherence of X-band SAR data in general is low over vegetation (PERKO et al. 2011) and thus, in the best case may be used only to differentiate vegetation and non-vegetation. Furthermore several TanDEM-X coherence measurements are available for the entire Earth's land surface and thus ideally suited for reference mapping of tropical forests. The results will be verified with more field data within other test sites. In addition, other forest parameters (e.g. tree height, biomass) will be assessed for this peat swamp area.

\section{References}

Koch, B., Heyder, U. \& Weinacker, H. (2006), Detection of Individual Tree Crowns in Airborne Lidar Data. Photogrammetric Engineering \& Remote Sensing, (72) 4, 357363.

Krieger, G., Moreira, A., Fiedler, H., Hajnsek, I., Werner, M., Younis, M. \& Zink, M. (2007), TanDEM-X: A Satellite Formation for High-Resolution SAR Interferometry. IEEE Transactions on Geoscience and Remote Sensing, 45, 3317-3341.

Perko, R., Raggam, H., Deutscher, J., Gutjahr, K. \& Schardt, M (2011), Forest Assessment Using High Resolution SAR Data in X-Band. Remote Sensing, 3, 792-815.

Popescu, S. C. \& Wynne, R. H. (2004), Seeing the Trees in the Forest: Using Lidar and Multispectral Data Fusion with Local Filtering and Variable Window Size for Estimating Tree Height. Photogrammetric Engineering \& Remote Sensing, 70 (5), 589604.

Schlund, M., Von Poncet, F., Kuntz, S. \& Schmullius, C. (2012), Importance of bistatic SAR features from TanDEM-X for forest mapping and monitoring. ForestSAT 2012, 11-14th September 2012, Corvallis, Oregon, USA.

Toraño Caicoya, A., Kugler, F., Papathanassiou, K. \& HajnseK, I. (2012), Boreal forest biomass classification with TanDEM-X. IEEE international Geosience and Remote Sensing Symposium (IGARSS), Munich, Germany, 3439-3442. 